\title{
Influence of graphene oxide nanofluids and surfactant on thermal behaviour of the thermosyphon
}

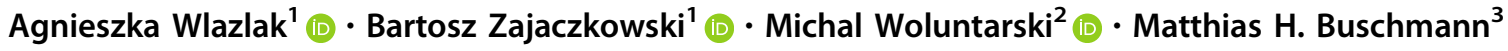

Received: 16 February 2018/Accepted: 2 August 2018/Published online: 17 August 2018

(C) The Author(s) 2018

\begin{abstract}
The paper presents a thermal performance analysis of a thermosyphon filled with graphene oxide nanofluid. It focuses on factors influencing thermal resistance and geyser boiling processes, such as the presence of surfactant (here: sodium dodecyl sulphate), the time-related deterioration of nanoparticles, and working conditions. Results indicate that GO nanofluids improved heat transfer at low heat loads and that enhancements were limited to the evaporator section. Although thermal resistance of the device was similar for all tested working fluids at high evaporator temperatures, the timedependent behaviour was different. Both water and GO nanofluid facilitated geyser boiling. Sodium dodecyl sulphate inhibited the phenomenon for pure water, but the same concentration of surfactant in the graphene oxide nanofluid did not show the same effect. SEM analysis showed that substantial amount of surfactant attached to the surface of graphene oxide flakes, which explains the previously described behaviour.
\end{abstract}

Keywords Thermosyphon · Nanofluid · Geyser boiling · Graphene oxide · Surfactant

\section{List of symbols}

p Pressure (mbar)

$R \quad$ Thermal resistance $\left(\mathrm{K} \mathrm{W}^{-1}\right)$

$t$ Temperature $\left({ }^{\circ} \mathrm{C}\right)$

$q$ Heat flux $\left(\mathrm{W} \mathrm{m}^{-2}\right)$

$Q \quad$ Amount of transferred heat (W)

$\vartheta \quad$ Temperature at given moment $\left({ }^{\circ} \mathrm{C}\right)$

$\Delta$ Difference

\section{Subscripts \\ c Condenser \\ e Evaporator \\ i Inlet \\ nf Nanofluid \\ o Outlet \\ ref Reference \\ th Thermosyphon}

Bartosz Zajaczkowski

bartosz.zajaczkowski@pwr.edu.pl

1 Faculty of Mechanical and Power Engineering, Wroclaw University of Science and Technology, 50-370 Wroclaw, Poland

2 Institute of Electronics Materials Technology, 01-919 Warsaw, Poland

3 Institut für Luft- Und Kältetechnik, 01309 Dresden, Germany

$\begin{array}{ll}\text { Abbreviations } \\ \text { CTAB } & \text { Cetyl trimethylammonium bromide } \\ \text { EDS } & \text { Energy dispersive spectrometer } \\ \text { Ga } & \text { Gum arabic } \\ \text { GF } & \text { Graphene } \\ \text { GO } & \text { Graphene oxide } \\ \text { rGO } & \text { Reduced graphene oxide } \\ \text { SEM } & \text { Scanning electron microscope } \\ \text { SDS } & \text { Sodium dodecyl sulphate } \\ \text { TPCT } & \text { Two-phase closed thermosyphon }\end{array}$

\section{Introduction}

Heat transfer improvement methods can be classified in one of two categories: active (e.g. application of external energy) and passive (e.g. modifications to the surface area, influence of the flow, or enhancement of fluid properties with various additives). This paper focuses on the last of above-mentioned passive methods: the introduction of nanoparticles that improve thermal properties of the base heat transfer fluid.

Prior to nanomaterials, attempts were made to create sustainable suspensions with microparticles. They did not reach expectations due to poor stability and tendency for clogging of channels, which noticeably increased pumping power $[1,2]$. Using nanoparticles (solid particles with at 
least one dimension less than $100 \mathrm{~nm}$ ) instead of microparticles seems to be a promising solution to rheological problems. Resulting suspensions are called nanofluids.

Nanofluids improve heat transfer coefficients in thermal systems. As a consequence of the tininess of the nanoparticles and their large specific surface area, a small volume fraction of particles leads to thermal improvement. Although viscosity increases when fluids are doped with nanoparticles, the negative effect is smaller than the possible enhancement of thermal conductivity [3].

The interest in nanofluids has grown substantially since their introduction by Choi and Eastman in 1995 [4]. They potentially overcome the greatest limitation of the base liquid (i.e. low thermal conductivity in comparison with solids) and thus allow for the development of high-performance heat transfer fluids [1, 2, 5, 6]. Most of the research on nanofluids focused on the heat transfer, pressure drop, and energy analysis [1, 2, 7-15]. These main performance parameters depend on broadly researched fundamental properties like thermal conductivity, viscosity, density, and specific heat capacity [3, 16-23]. Most recently, Estellé et al. [24] reviewed studies on surface tension and wetting behaviour of nanofluids which are key parameters for understanding heat transfer during boiling.

Many papers on graphene (GF) and graphene oxide (GO) nanoparticles have been published since it was first isolated in 2004, but only a fraction discusses graphenebased nanofluids [1, 7, 8, 21, 25-29]. In this group, only a few works contemplate graphene nanofluids as working fluids for thermosyphons and heat pipes [27-29]. Published results are case-depended and difficult to generalise because even small deviations in a synthesis method, duration of sonification, or the presence of surfactant change thermophysical properties and affect stability of the final suspension [30].

\section{Two-phase closed thermosyphon (TPCT)}

A two-phase closed thermosyphon is a sealed tube filled with properly selected working fluid. The device consists of three sections: evaporator section, adiabatic section, and condenser section (Fig. 1). Working fluid boils due to heat supplied to the evaporator from the external source. Vapour flows through the adiabatic section to the above-located condenser section where heat is released to the cooling medium. Condensed liquid returns to the evaporator section due to gravity.

The main purpose of using nanofluids in thermosyphons is to lower overall thermal resistance of the device below what is possible with a pure working fluid. Few explanations for this effect can be found in the literature, e.g. enhanced thermal properties of nanofluids, nanoparticle

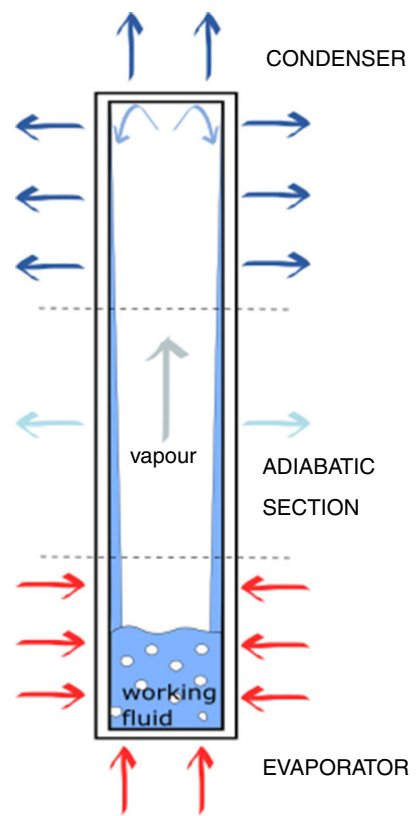

Fig. 1 Scheme of the two-phase closed thermosyphon

interaction with the heater surface, and altered boiling process $[1,2,31]$. It was confirmed that nanofluids do not affect the thermal behaviour of the condenser [5, 6].

Several reviews on operation and application of thermosyphons employing nanofluids have been published in recent years $[2,7,8,10,25,26]$, but only a few investigations discussed graphene-based nanofluids [6, 27-29]. Azizi et al. [27] showed experimentally that a graphene nanofluid stabilised with a gum arabic increased thermal efficiency of thermosyphon of $10 \%$ compared with water. Amiri et al. [28] found that adding graphene nanoplatelets to water improved heat transfer efficiency. Thermal resistance was lowered with an increase in both power input and concentration. Enhancements of thermophysical properties of nanofluids were more significant for covalent nanofluids (the acid-functionalised nanoplatelet-water nanofluid) than for non-covalent ones (functionalised with sodium dodecyl benzene sulphonate SDBS). Kim and Bang [6] investigated the influence of graphene oxide nanofluids on heat pipe performance. Thermal resistance was lowered by about $25 \%$ compared with water. The results were better for a concentration of $0.01 \mathrm{vol} \%$ than for $0.03 \mathrm{vol} \%$. The authors suggested that this was due to densely packed deposition which reduced permeability of the wick. No effect was registered in the condenser section. Nazari et al. [29] studied a pulsating heat pipe filled with graphene oxide nanofluid. Thermal resistance was decreased by up to $42 \%$ with the addition of GO, but an optimum of its concentration existed $\left(0.25 \mathrm{~g} \mathrm{~L}^{-1}\right)$. It was caused by the increase in dynamic viscosity which had a crucial impact on the operation of the pulsating heat pipe. The summary 
of previous research on heat pipes employing graphenebased nanofluids is presented in Table 1.

As the results are scarce, it is necessary to study the effects that drive behaviour of graphene oxide-based nanofluids in thermosyphons.

\section{Effects}

In this work, we closely study three factors that influence operation of the TPCT: deposition of nanoparticles on the heat transfer surface, occurrence of geyser boiling, and the influence of surfactants.

\section{Deposition of nanoparticles}

During boiling, nanoparticles tend to form layers on the heated surface. The mechanism responsible for such deposition is probably a microlayer evaporation, as proposed by Kim et al. [32] and later experimentally confirmed by Kwark et al. [33]. The layer of liquid between the heated surface and the growing bubble evaporates quickly causing local increases in concentration and decreases in distance between nanoparticles. As a consequence, nanoparticles that were initially contained in a microlayer build a porous layer on the heated surface.

Distribution of particles depends on their hydrophilicity [16]. Initially, strongly hydrophobic nanoparticles are distributed uniformly in the droplet and evaporation takes place mostly at the vapour-liquid boundary. Liquid flows outward from the centre of the droplet to its edge carrying suspended nanoparticles. In result, nanoparticles get highly concentrated along the boundary, which phenomenon is called the coffee ring effect [34]. Moderately hydrophobic particles are distributed in loosely packed structures on the vapour-liquid interface. Inter-particle interactions deform interfaces and prevent particles from reaching the drop edges producing irregular and much rougher deposition layer than strongly hydrophobic particles [16].

\section{Geyser boiling}

Geyser boiling is a kind of instantaneous boiling where the working fluid gathered above a bubble is propelled to the condenser section $[35,36]$. The problem of geyser boiling often remained unnoticed, and there were only a few mentions of it in the available literature [37-40]. There is only one study of geyser boiling occurring in thermosyphons filled with gold nanofluids [41], and no study on graphene oxide nanofluids.

Geyser boiling (or the geyser effect) in thermosyphons is schematically shown in Fig. 2. It consists of four phases: superheating of the working fluid in the evaporator (a), development and quick growth of the bubble (b), bubble expansion and propulsion of the fluid located above the bubble, even up to the top of condenser [5, 36] (c), and return of the displaced liquid (d). The cycle repeats itself.

The amplitude and frequency of geyser boiling depend on working conditions, including heat load, working fluid, geometry of the device, its inclination angle, and filling ratio [37-39]. The phenomena occur at low pressures, for large filling ratios, or during start-ups and are classified as two-phase compound relaxation instability [40].

\section{Influence of surfactants}

Till now, in the literature, little attention was paid to the influence of surfactants on heat transfer of carbon-based nanofluids during boiling [28, 42]. Several hints can be found in more general papers on thermophysical properties of nanofluids themselves.

Shanbedi et al. [43] experimentally determined thermophysical properties of carbon nanotubes in the presence of three different surfactants: sodium dodecyl sulphate (SDS), cetyl trimethylammonium bromide (CTAB), and gum arabic (GA). They found that surface tension of nanofluids decreased with the rise in temperature and SDS concentration. Viscosity decreased with increasing concentration of surfactant and for higher temperatures under

Table 1 A summary of previous research on heat pipe employing graphene-based nanofluids

\begin{tabular}{llllc}
\hline Reference & $\begin{array}{l}\text { Type } \\
\text { of HP }\end{array}$ & Type of graphene-based NF & Concentration of nanoparticles & Maximum enhancement \\
\hline Azizi et al. [27] & TS & Graphene/water + GA & $0.02 \%-1$ mass/\% & $10 \%$ \\
Amiri et al. [28] & TS & $\begin{array}{l}\text { Graphene nanoplatelets/ } \\
\text { water + SDBS or COOH }\end{array}$ & $0.025-0.1$ mass/\% & $35 \%$ (SDBS); 68\% \\
Kim and Bang [5] & HP & Graphene oxide & $0.01-0.03$ vol./\% & $25 \%$ \\
Nazari et al. [12] & PHP & Graphene oxide & $0.25-1.5 \mathrm{~g} \mathrm{~L}^{-1}$ & $42 \%$ \\
\hline
\end{tabular}

$N F$ nanofluid, $T S$ thermosyphon, $H P$ heat pipe, $P H P$ pulsating heat pipe, $G A$ arabic gum, SDBS sodium dodecyl benzene sulphonate 
Fig. 2 Scheme of geyser boiling. Phases a-d as follows: superheating of the working fluid in the evaporator (a), bubble development and its quick growth of the bubble (b), bubble expansion and propulsion of the fluid located above the bubble, even up to the top of condenser [5, 36] (c), and downfall return of the displaced liquid (d)

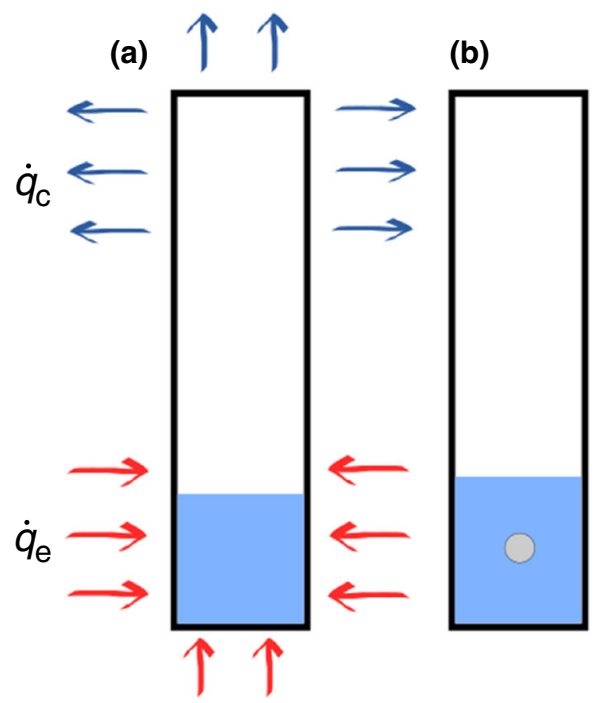

(c)

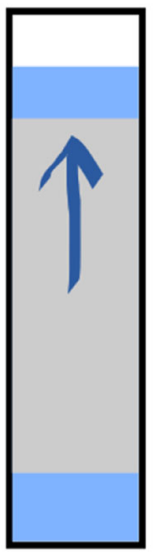

(d)

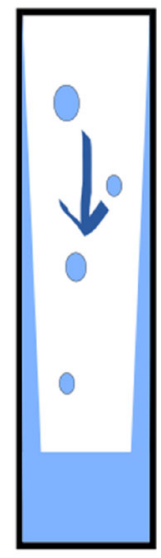

constant share rate. Density decreased with increasing temperature, and there were almost no effects caused by addition of a surfactant.

Huminic et al. [19] determined the influence of surfactant on properties of nanofluids based on $\mathrm{FeC}$. The authors found that thermal conductivity of surfactant/water solution (water with $3 \mathrm{~g} \mathrm{~L}^{-1} \mathrm{CMCNa}$ ) was similar to pure water what suggests that the possible enhancement in thermal conductivity was due to the presence of nanoparticles. The situation was different when considering viscosity. The addition of surfactant into water increases its viscosity; thus, the viscosity of nanofluids was affected by both nanoparticles and the chemical additive. The authors showed that although the surface tension of surfactant solution was considerably lower than the one of water, the surface tension may change diversely when considering nanofluids. For small concentrations of $\mathrm{FeC}$ particles (0.1 mass $\%$ and 0.5 mass $\%$ ), the surface tension was lower than the one of water. But when 1.0 mass $\%$ was employed, the surface tension exceeded the value for water.

\section{Summary}

In this paper, we study the performance of graphene oxide (GO) nanofluids in a thermosyphon. In the following sections, we analyse GO nanofluids behaviour with and without the addition of sodium dodecyl sulphate (SDS) and compare the results with two reference fluids: pure water and SDS water solution (without GO particles).

Firstly, we determined to what degree GO nanofluids affected the thermal resistance of the TPCT and how the presence of surfactant impacted its operation. Secondly, we studied the influence of boiling process on the mediumterm stability of GO nanofluid and deterioration of GO nanoparticles. Finally, we analysed the occurrence and consequences of geyser boiling in the TCPT. The latter was possible thanks to especially located high-resolution pressure gauges that allowed us to register and record any occurrences of geyser boiling. The influence of boiling process on graphene oxide flakes was studied using SEM photography of particles that remained in the working fluid after the experiment.

\section{Experimental}

\section{Experimental set-up and procedure}

All experiments were carried out using a closed-loop twophase thermosyphon (shown in Fig. 3) made of a 1800-mm copper pipe with an inner diameter of $20 \mathrm{~mm}$ and wall thickness of $1 \mathrm{~mm}$, which was insulated with a $20-\mathrm{mm}$ Armaflex shell. Evaporator and condenser sections (each $400 \mathrm{~mm}$ long) were wrapped with a coiled copper tube with an inner diameter of $4 \mathrm{~mm}$.

After evacuation, the thermosyphon was filled with $85 \mathrm{~mL}$ of working fluid. Water was used as heating and cooling medium. The inlet and the outlet temperatures were measured with Pt100 - elements with a working range from $-20{ }^{\circ} \mathrm{C}$ to $+150{ }^{\circ} \mathrm{C}$ and with an accuracy of $\pm 1 / 3(0.3+0.005 \vartheta)$, where $\vartheta$ is the value of the determined temperature. At the highest analysed temperature $\left(85^{\circ} \mathrm{C}\right)$, the maximum uncertainty was equal to \pm $0.24 \mathrm{~K}$. Temperatures of the working fluid in the evaporator section were measured with a temperature sensor made according to the specification matching the thermodynamics and the geometry of thermosyphon. It consisted of six Pt100-elements positioned at different heights of the evaporator section (Fig. 3). Their accuracy in the range of 
Fig. 3 Photograph of the experimental set-up

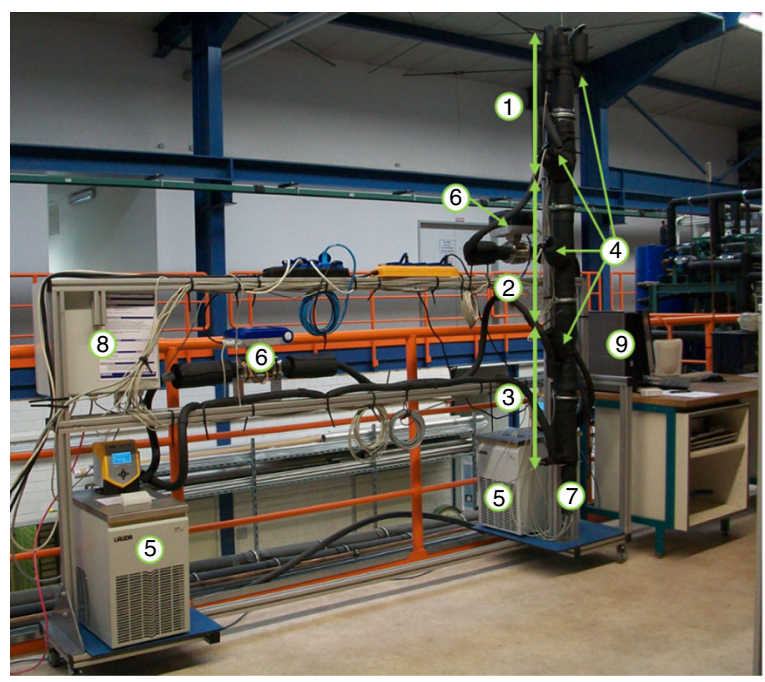

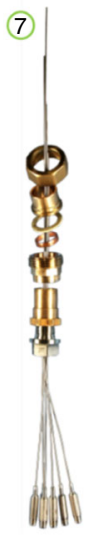

1 - condenser

2 - adiabatic section

3 - evaporator

4 - pressure transmitters

5 - thermostats

6 - flowmeters

7 - tailor made

temperature sensors

8 - data acquisition

system

9-PC temperatures from $-20^{\circ} \mathrm{C}$ to $+150{ }^{\circ} \mathrm{C}$ was $\pm(0.15+$ $0.002 \vartheta)$. Thus, considering the highest temperature in the test rig $\left(85^{\circ} \mathrm{C}\right)$, the maximum uncertainty was $\pm 0.32 \mathrm{~K}$.

Internal pressure was measured at three different positions along the pipe with a measurement range $0-400 \mathrm{~Pa}$ and at the top of the device with two different measurement ranges $\left(0-10^{4}\right.$ and $\left.0-10^{5} \mathrm{~Pa}\right)$ to ensure high resolution of the data. All transmitters worked at a frequency of $1 \mathrm{kHz}$ and an accuracy of $\pm 0.25 \%$. Volume fluxes of heating and cooling water were measured with magneto-inductive Krohne Optiflux 5100C flow meters. The sample rate was $410 \mathrm{~ms}$. Inlet temperatures of heating and cooling water cycles were provided by two LAUDA Eco RE $1050 \mathrm{GW}$ thermostats with temperature constancy of $\pm 0.02 \mathrm{~K}$. All the measured parameters were monitored and recorded with a ProfiSignal software.

Volume fluxes of heating and cooling cycles were kept constant at value $12 \pm 0.055 \mathrm{l} \mathrm{h}^{-1}$. For each working fluid, two measurement series were conducted with inlet temperatures of cooling water of $15^{\circ} \mathrm{C}$ and $25^{\circ} \mathrm{C}$. The temperature of the heating medium leaving the thermostat varied between 30 and $85^{\circ} \mathrm{C}$ at $5 \mathrm{~K}$ steps. Despite the insulation, we registered heat losses between heat source and the thermosyphon. Thus the maximum inlet temperature of heating water obtained for $85^{\circ} \mathrm{C}$ case was $80.56 \pm 0.23{ }^{\circ} \mathrm{C}$. Mean temperature of the inlet cooling water was $25.06 \pm 0.14^{\circ} \mathrm{C}$ for $25^{\circ} \mathrm{C}$ case and $14.59 \pm 0.12{ }^{\circ} \mathrm{C}$ for $15{ }^{\circ} \mathrm{C}$ series.

All conducted experiments followed a procedure established in ILK to ensure repeatability and comparability of results. The procedure started with a running-in period. After 30-60 min, inlet temperatures at the evaporator and the condenser, as well as evaporator and condenser volume fluxes, usually reached steady-state operation. From this moment, all measurements were recorded over a period of $60 \mathrm{~min}$. Time averaged data were obtained by integration over the measurement period. Experiments were carried out at set condenser inlet temperature and varying evaporator inlet temperature (at $5 \mathrm{~K}$ increments). After experimental series with a given fluid, the thermosyphon was opened and the working fluid was carefully removed for analysis. The interior of the evaporator was inspected using an endoscopic SOMIKON HD camera in order to identify and evaluate the quality of porous layers deposited from nanoparticles. The inner surface of the entire thermosyphon was then carefully cleaned with lint-free flannel and by rinsing with acetone and distilled water. Afterwards, the surface got visually examined again using the camera. Remaining cleaning fluid was extracted by vacuuming. The device was then assumed ready for the next experimental series.

\section{Working fluids}

The thermosyphon was filled with two kinds of nanofluids based on graphene oxide (GO). GO flakes were prepared at ITME, Warsaw, Poland by means of a modified Hummers method [44] that is schematically presented in Fig. 4.

Source graphite material was oxidised chemically through a treatment with a solution of $95 \%$ sulphuric acid (proportion of graphite to acid $10 \mathrm{~g}$ per $1 \mathrm{~L}$ ), sodium nitrate (mass ratio to graphite $2: 3$ ), and potassium permanganate (mass ratio to graphite $6: 1$ ) in the temperature of $50{ }^{\circ} \mathrm{C}$. After oxidation, slurry was diluted in deionised water and $\mathrm{H}_{2} \mathrm{O}_{2}$ was added. Hydrogen peroxide acts like an inhibitor for the second stage of an oxidation [45]. This stage of a process is caused by $\mathrm{Mn}_{2} \mathrm{O}_{7} \mathrm{MnO}^{3+}$ in diluted acid. The violence of the oxidation process leads to flakes damages. Presence of hydrogen peroxide lowers the oxidation state of manganese, allowing to form $\mathrm{Mn}^{2+}$ ions and manganese sulphate which is well soluble in water. 
Fig. 4 Production route of graphene oxide nanofluids

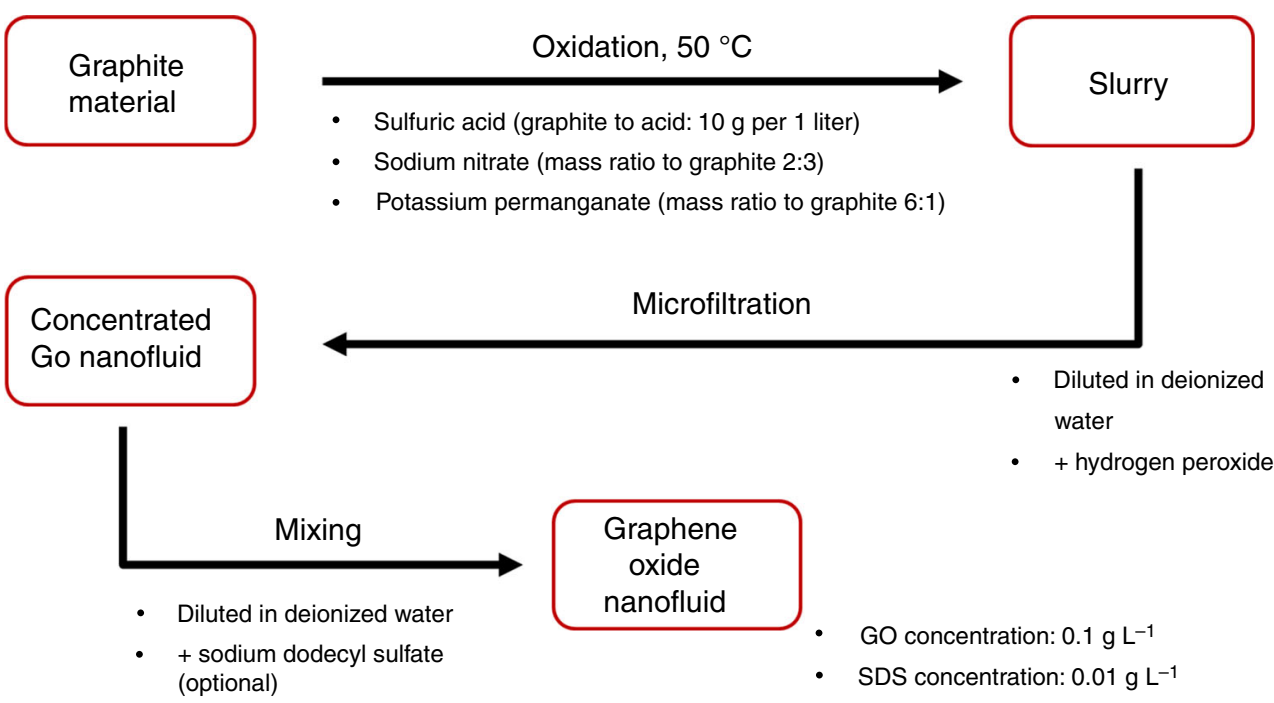

In the next step, the solution was cleaned in a microfiltration device. The resulting solution of concentrated graphene oxide (GO) was diluted to ensure a concentration of $0.1 \mathrm{~g} \mathrm{~L}^{-1}$. Half of the nanofluid was enhanced with 0.01 $\mathrm{g} \mathrm{L}^{-1}$ of sodium dodecyl sulphate (SDS), and both samples were mixed for $4 \mathrm{~h}$. Part of the samples were used in the thermosyphon, and the remaining ones were further stored for observation. After 4 months of visual monitoring, no optical signs of sedimentation were noticed. There was no difference in external appearance in any of the stored samples. Particles in the samples used in the thermosyphon exhibited sedimentation which is described in detail in "Surface of the evaporator and SEM photographs of particles" section and presented in Fig. 8.

In order to obtain reliable data, all experiments followed the measurement procedure explained in "Experimental set-up and procedure" section. As distilled water was the base fluid in all cases, DI water was also considered as a base line. Additionally, a solution of sodium dodecyl sulphate (SDS) was tested to obtain the reference data for the SDS stabilised nanofluid. The SDS solution contained the same amount of SDS as the graphene oxide nanofluid with SDS. This approach allowed for the separation of effects triggered by nanoparticles and by surfactant. All tested working fluids are presented in Table 2.

\section{Results and discussion}

\section{Time averaged data}

All results presented in this section are estimated as mean values from experiments lasting one hour. One of the crucial indicators of the heat transfer efficiency of a thermosyphon is its thermal resistance, shown in Fig. 5. It is defined according to [5] as:

$R_{\mathrm{th}}=\frac{\bar{t}_{\mathrm{e}}-\bar{t}_{\mathrm{c}}}{\bar{Q}_{\mathrm{c}}}$,

where $\bar{t}_{\mathrm{e}}$ and $\bar{t}_{\mathrm{c}}$ are the mean temperatures of evaporator and condenser, respectively; $\bar{Q}_{\mathrm{c}}$ is the heat released in the condenser section. The error analysis is based on Gaussian law of error propagation. The maximum values of uncertainty are $0.08 \mathrm{~W} \mathrm{~K} \mathrm{~K}^{-1}$ for $t_{\mathrm{ci}}=25^{\circ} \mathrm{C}$ series and $0.24 \mathrm{~W} \mathrm{~m}^{-1} \mathrm{~K}^{-1}$ for $t_{\mathrm{ci}}=15{ }^{\circ} \mathrm{C}$ series.

Thermal resistance of the device decreases with the increase in the heat flux and achieves almost a constant value of $0.078 \pm 0.003 \mathrm{~W} \mathrm{~K}^{-1}$ for inlet temperatures of heating medium higher than $55{ }^{\circ} \mathrm{C}$ (in case of $t_{\mathrm{ci}}=25{ }^{\circ} \mathrm{C}$ series) and $50{ }^{\circ} \mathrm{C}\left(t_{\mathrm{ci}}=15{ }^{\circ} \mathrm{C}\right.$ series $)$ for all tested fluids. Considerable reduction in thermal resistance caused by nanofluid is visible only at low evaporator temperatures. In this temperature range, the use of nanofluids yields to both lower the thermal resistance of the device and increase the amount of transferred heat.

The difference between red crosses and red squares indicating the same working fluid (GO nanofluid without SDS, $25{ }^{\circ} \mathrm{C}$ case) suggests that the results exhibited transient-like characteristics what is in agreement with other studies [33, 46]. The first measurements conducted after filling the device with nanofluid (red cross, GO, $25^{\circ} \mathrm{C}$ case) showed thermal resistance approx. $20 \%$ lower than in the case of water. Thermal resistance decreased by about $60 \%$ compared to water when experiments were repeated after completing the whole first series of measurements (red squares, GO, $25{ }^{\circ} \mathrm{C}$ case). At the beginning of each part of experiments, nanoparticles were evenly dispersed, but during boiling they deteriorated and formed layers on the inner surface of the evaporator. Certain amount of time 
Table 2 Fluids used as working fluid in the thermosyphon

\begin{tabular}{|c|c|c|c|c|c|c|}
\hline $\begin{array}{l}\text { Working } \\
\text { fluid }\end{array}$ & $\begin{array}{l}\text { Base } \\
\text { fluid }\end{array}$ & Nanoparticles & $\begin{array}{l}\text { Particles } \\
\text { concentration }\end{array}$ & $\begin{array}{l}\text { Mean size } \\
\text { of particles* }\end{array}$ & Surfactant & $\begin{array}{l}\text { Surfactant } \\
\text { concentration }\end{array}$ \\
\hline Water & Water & - & - & - & - & - \\
\hline SDS solution & Water & - & - & - & Sodium dodecyl sulphate (SDS) & $0.01 \mathrm{~g} \mathrm{~L}^{-1}$ \\
\hline GO fresh & Water & Graphene oxide (GO) flakes & $0.1 \mathrm{~g} \mathrm{~L}^{-1}$ & $901 \mathrm{~nm}$ & None & - \\
\hline $\mathrm{GO}+\mathrm{SDS}$ & Water & Graphene oxide (GO) flakes & $0.1 \mathrm{~g} \mathrm{~L}^{-1}$ & $769 \mathrm{~nm}$ & Sodium dodecyl sulphate (SDS) & $0.01 \mathrm{~g} \mathrm{~L}^{-1}$ \\
\hline
\end{tabular}

*Measured with Malvern Nano-ZS in the temperature range of $25-75{ }^{\circ} \mathrm{C}$. DLS is a highly reliable method for spherical particles. As graphene flakes have usually the thickness of approx. $2-10 \mathrm{~nm}$ and significantly greater length, these values should be treated as a rough estimation of hydrodynamic diameters
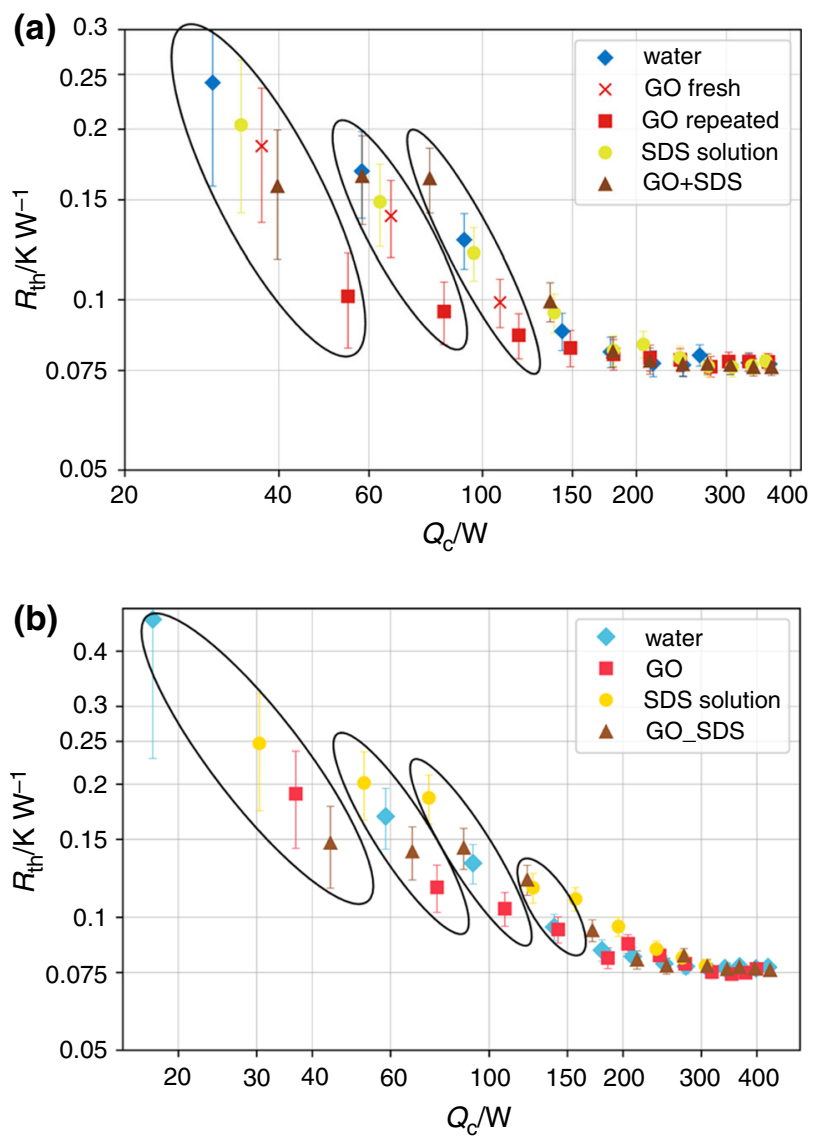

Fig. 5 a Thermal resistance of all working fluids in dependency on heat realised in the condenser for condenser temperature of $25^{\circ} \mathrm{C}$. b Thermal resistance of all working fluids in dependency on heat realised in the condenser for condenser temperature of $15^{\circ} \mathrm{C}$. Circles indicate the same inlet temperature of heating medium.

was required to see the effect because boiling heat transfer improvement was caused mainly by a GO coating on the surface.

Inspection with an endoscopic camera indicated that the inner surface of the evaporator was coated with a GO layer (see Fig. 8 right). Such deposition of nanoparticles influences surface roughness in three ways depending on the size of nanoparticles and initial roughness of surface [31]:

- nanoparticles size is smaller than the surface roughness-nanoparticles fill the surface cavities and reduce therewith the surface roughness,

- nanoparticles size is smaller than the characteristic length scale of surface roughness, but the difference is not that significant (e.g. nanoparticle size $47 \mathrm{~nm}$ and characteristic length scale of roughness $0.524 \mathrm{~mm}$ ) the number of active nucleation sites is multiplied by splitting single cavities into several nucleation sites,

- size of nanoparticles or its agglomerates is greater than cavities-surface roughness and number of nucleation sites may change diversely.

By these effects, the wettability of the surface alters [31, 47]. Moreover, the density of the nucleation sites stimulating phase change may increase [5], which in turn further accelerates boiling process. A next effect-increasing the evaporator surface available for the boiling process by depositing nanoparticles-is ruled out as cause of an increased heat transfer. The reason is that the surface increase by deposited nanoparticles is tiny compared with the uncoated evaporator surface. However, with the experimental technique employed here it was not possible to examine these effects en detail.

In the case of porous layer deposition, the interplay of wettability and porosity is called wickability [13]. Deposited nanolayers influence chemistry and structure of the base surface and modify the force balance at the triple line. All mentioned factors have a crucial impact on characteristics of the heat transfer process during boiling $[13,31,48,49]$. No effect was found in the condenser section what agrees with previous studies [5, 42].

Reduction of GO occurs at approx. $50-60{ }^{\circ} \mathrm{C}$; thus, it takes place during boiling. Although reduced graphene oxide (rGO) is hydrophobic, it can still absorb water into its structure after some period of time [50] leading to capillary wicking. This observation agrees with measurements of 
graphene oxide-water nanofluids conducted by Kamatchi et al. [17], before and after boiling on both smooth and rough surfaces. The study confirmed dual wettability of rGO caused by activation of the carboxyl groups on the flake surface. Contact angle decreased with time for all tested cases. In result, permeability increased, creating proper conditions for capillary wicking $[50,51]$.

Graphene oxide has high thermal conductivity (up to $\left.3500-5300 \mathrm{~W} \mathrm{~m}^{-1} \mathrm{~K}^{-1} \quad[52,53]\right)$ and surface area (736 $\mathrm{m}^{2} \mathrm{~g}^{-1}$ [54] or even up to $2630 \mathrm{~m}^{2} \mathrm{~g}^{-1}$ [53]). Particles deposited on the heating surface form a thermal bridge between the wall and working fluid. It worked well for low heat loads where the thermal conductivity played a more important role than for high temperatures. Here, a welldeveloped boiling process was the main mechanism of heat transport.

The amount of heat transferred by the thermosyphon changed for various working fluids, even if all other working conditions remain the same. Figure 6 presents the degree of an enhancement obtained for a given fluid $Q_{\mathrm{cNF}}$ compared to the base value determined for water $Q_{\mathrm{c} \text {, ref: }}$ :

$\Delta q_{\mathrm{c}}=100 \%\left(\frac{Q_{\mathrm{c}, \mathrm{nf}}}{Q_{\mathrm{c}, \mathrm{ref}}}-1\right)$.

Enhancement was achieved only for an inlet temperature of the heating medium below $50{ }^{\circ} \mathrm{C}$ for both series. The highest improvement was obtained for pure GO nanofluid. GO + SDS nanofluid presented a slight progression compared to the SDS solution for the low values of $t_{\mathrm{ei}}$. Both fluids showed values lower than those for water; however, the trend was not as stable as for GO series. The real inlet temperature of heating water $\left(t_{\mathrm{ei}}\right)$ was almost constant for all the fluids; thus, the differences in results were not caused by additional variations in external conditions.

The boiling curves are shown in Fig. 7. They denote heat supplied to the evaporator in dependence of the overheating at the evaporator wall. Overheating is the difference between temperature of the evaporator wall and the boiling temperature at a given pressure. GO nanofluid affected the boiling regimes occurring in the device. For small heat loads, boiling curves were shifted to the left, which means that more heat was removed from the surface at the same temperature or that the surface temperature was lower. When the overheating exceeded the values of $10 \mathrm{~K}$ (for $t_{\mathrm{ci}}=25^{\circ} \mathrm{C}$ ) or $13 \mathrm{~K}\left(t_{\mathrm{ci}}=15^{\circ} \mathrm{C}\right.$ ), there were no noticeable differences in data for different working fluids. GO + SDS nanofluid behaved similar to water. Exept an inlet temperature of the heating medium equal to $50{ }^{\circ} \mathrm{C}$ and $55{ }^{\circ} \mathrm{C}$ and cooling medium of $15{ }^{\circ} \mathrm{C}$, where two parallel states of boiling were obtained. The device switched between these two states without any pattern, which was not seen in any other experimental series. It was probably
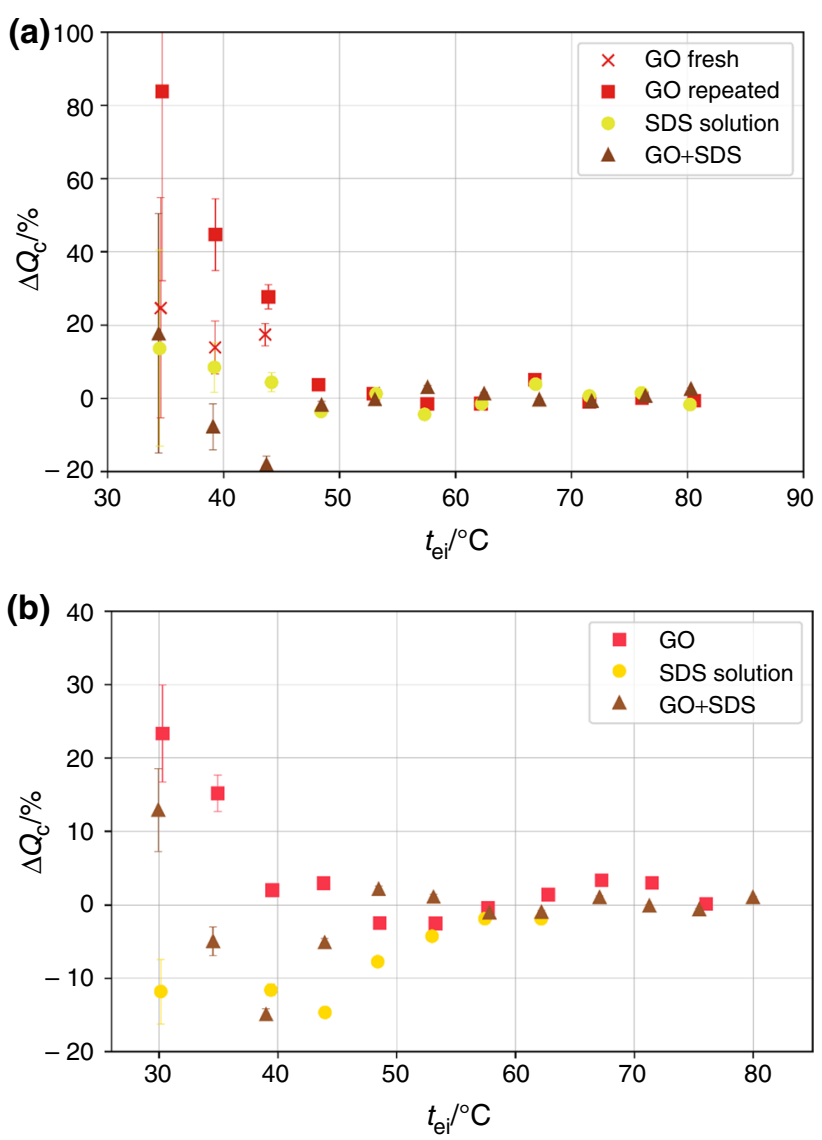

Fig. 6 a Increase in heat transferred by different working fluids compared to water in dependency of evaporator inlet temperature (upper: $25^{\circ} \mathrm{C}$ case). b. Increase in heat transferred by different working fluids compared to water in dependency of evaporator inlet temperature $\left(15^{\circ} \mathrm{C}\right.$ case $)$

caused by reduction of GO which may happen at given temperatures.

\section{Surface of the evaporator and SEM photographs of particles}

Deposited GO/rGO particles are exposed as a black porous layer in Fig. 8 (right). A photograph taken inside the thermosyphon with an endoscopy camera shows a porous layer found approx. $200 \mathrm{~mm}$ from the bottom of the device. Energy-dispersive spectrometer (EDS) analysis carried out by Kim et al. [55] confirmed that layers formed during the boiling of nanofluids are indeed made of nanoparticle material.

Figure 8 (left) presents fluids taken out from the device after finishing all the experiments compared to the fresh ones. The change of colour, as well as agglomerated particles that were not stuck to the wall, is easily noticeable. The sheet shape of graphene oxide was destroyed, as presented in Fig. 9. Figure 9a shows SEM photographs of 

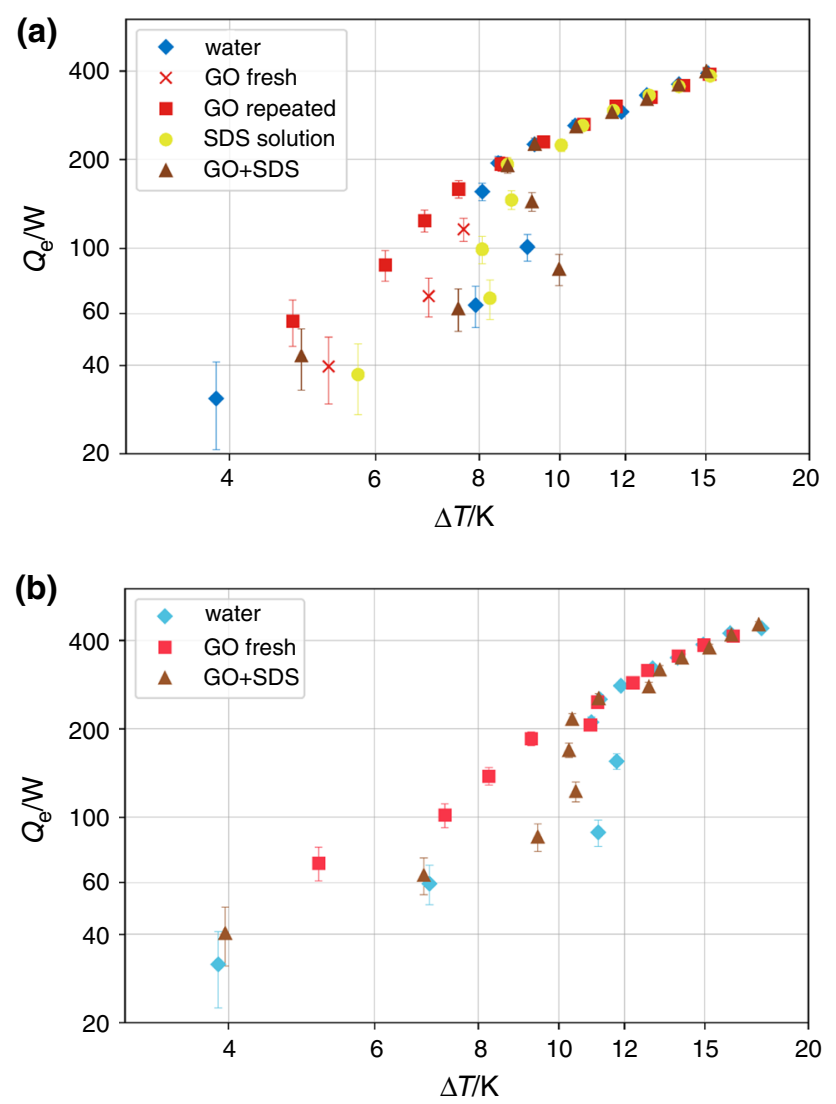

Fig. 7 a Boiling curves for inlet temperature in condenser of $25^{\circ} \mathrm{C} . \mathbf{b}$ Boiling curves for inlet temperature in condenser of $15{ }^{\circ} \mathrm{C}$

diluted and dried fresh material, while Fig. 9b-d presents nanoparticles removed from the device after experiments. Shapes and sizes of the structures became very irregular. They were either similar to a sponge or few connected sheets like graphene paper or other chaotic texture. Crystals visible in Fig. 9d are the SDS that attached to the flakes of graphene oxide. It inhibited strong interaction between particles and evaporator wall which resulted in worse thermal capacity of the device employing GO-SDS than pure GO nanofluid.

\section{Time-dependent data}

Although no significant differences in averaged thermal capabilities of the device are reported for high temperatures in the evaporator, time-dependent behaviour in this region highly depended on the employed working fluid (Fig. 10). Water and graphene oxide nanofluid behaved in similar ways, and phase transition occurred through geyser boiling for high heat loads. In general, the amplitude and frequency of the events depended on both temperatures, in the evaporator and in the condenser. An increase in temperature difference between evaporator and condenser resulted in shorter and less intensive geysers.

Employment of SDS solution prolonged periods of boiling between geysers at lower temperatures and completely prevented sudden events at the highest heat fluxes (see $t_{\mathrm{ci}}=25{ }^{\circ} \mathrm{C}, t_{\mathrm{ei}}=85{ }^{\circ} \mathrm{C}$ case, Fig. 10 upper middle plot). SDS, which is an anionic surfactant, reduces surface tension. According to the visualisation reported by Wang et al. [56], two mechanisms during boiling of surfactant may happen: bubble bursting and a strong jet flow phenomena. The first one prevents formation of large bubbles expelling further towards the condenser due to lower surface tension. The second deals with the traces of small bubbles ejected from the main bubble that appeared on the heater surface. After splitting, the main bubble decreases and dry-out spots are eliminated. When at least two unstable bubbles appear in a short distance from each other, the bubbles merge. After coalescence, surfactant molecules transfer to the connection point. Due to significant decrease in surface tension at this point, the merged bubble expands rapidly, which results in an explosion at the point with the lowest surface tension. Both mechanisms lead to smaller dry-out spots, more intense disturbance, and, as a result, improved heat transfer. Due to reduced surface tension, less energy is required to create the bubble and activation of nucleation sites in a clustered mode is promoted. It engenders higher bubbles departure frequency (affected also by cavity-cavity interaction, microlayer
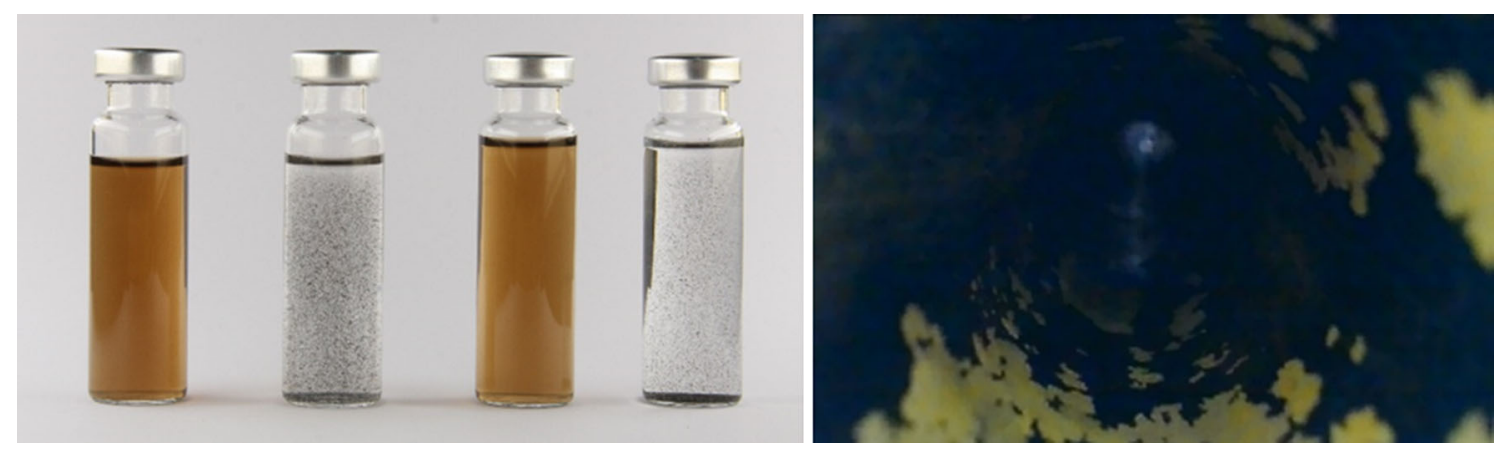

Fig. 8 Samples before and after use (left picture). First two are GO $\left(0.1 \mathrm{~g} \mathrm{~L}^{-1}\right)$ nanofluid without SDS; the second ones are with SDS addition $\left(0.01 \mathrm{~g} \mathrm{~L}^{-1}\right)$. Porous layer formed on inner surface of the evaporator after GO nanofluid boiling (right picture) 
Fig. 9 SEM pictures of GO particles: a fresh sheets, $\mathbf{b}-\mathbf{c}$ GO structures after experiments, d GO-SDS after experiments
Fig. 10 a Time-dependent pressure data at $\mathrm{p}_{3}$ for water, SDS solution, and GO + SDS nanofluid $\left(t_{\mathrm{ci}}=25^{\circ} \mathrm{C}\right.$, $\left.t_{\text {ei }}=80^{\circ} \mathrm{C}\right)$. b Time-dependent pressure data at $\mathrm{p}_{3}$ for water, SDS solution, and GO + SDS nanofluid $\left(t_{\mathrm{ci}}=15{ }^{\circ} \mathrm{C}\right.$, $\left.t_{\mathrm{ei}}=65^{\circ} \mathrm{C}\right)$
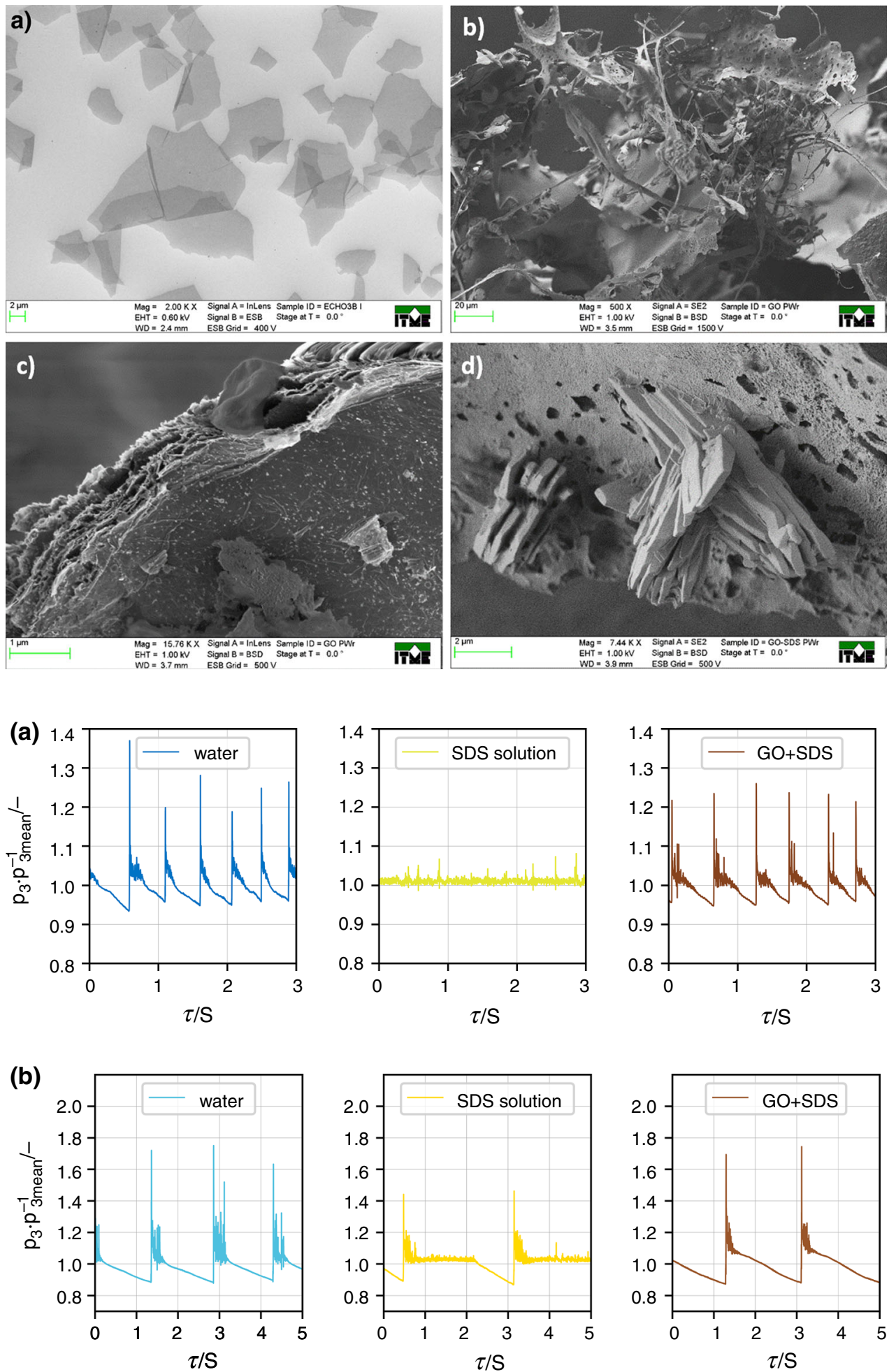

evaporation, and coalescence of bubbles), a more vigorous boiling process, and smaller bubble diameters [56, 57].

Unexpectedly, graphene oxide nanofluid stabilised with the same concentration of SDS did not follow the behaviour of the surfactant solution. Geyser boiling appeared again with similar amplitude and slightly lower frequency than for water. From Fig. 9d, we suspect that the surfactant was no longer present in the fluid (or its concentration was significantly reduced) due to possibility of SDS attachment to the surface of graphene flakes. As any other thermophysical property, surface tension of nanofluids depends on nanoparticle content (concentration) and additional 
surfactant content. It is known from experimental determination of surface tension of GO nanofluids that surface tension is lowered $[10,24]$. Most recently, Cabaleiro et al. [21] showed that the addition of graphene oxide particles with concentration between 0.0005 and 0.1 vol\% without surfactant causes the decrease in surface tension with a maximum reduction of about $3 \%$. Based on these findings, an influence of nanoparticle and surfactant content of the working fluid on the surface tension and therewith on the boiling process can be expected. Thus, SDS attachment to the flakes reduced its influence on the surface tension of fluid and consequently on the boiling process. This shows that the chemistry of the particle plays an important role in preventing geyser boiling.

Geyser boiling may influence the process of nanolayer deposition. Because the boiling process is volatile and intermittent, it is not clear whether the microlayer evaporation takes place in the pool. However, centrifugal splashing of fluid caused by the geyser event produced similar results when the narrow fluid film dries out on the wall. We found traces of the nanoparticles about $200 \mathrm{~mm}$ to $400 \mathrm{~mm}$ above the bottom of the evaporator (working fluid at rest reached about $270 \mathrm{~mm}$ ). The location suggests that both mechanisms actively contribute to formation of the layer.

\section{Conclusions}

An experimental study on thermosyphon employing graphene oxide $\left(0.1 \mathrm{~g} \mathrm{~L}^{-1}\right)$ nanofluids with and without the addition of surfactant (sodium dodecyl sulphate, SDS) is conducted. Results are compared with a baseline data obtained for distilled water and SDS water solution. The main findings are as follows:

- GO nanofluids improved heat transfer capabilities of the thermosyphon, but the effect was noticeable only at low temperatures of the evaporator section. Exchanging a traditional working fluid (like water) with a waterbased nanofluid leaded to a shift of the working point. This took place even if inlet temperatures and the volume fluxes in heating/cooling coils were kept unchanged.

- For high heat loads, the difference between thermal performances of analysed fluids was negligible, regardless of the presence of nanoparticles.

- The nanofluid did not influence heat transfer in the condenser. The positive influence of the nanofluid on heat transfer was limited to the evaporator section.

- Heat transfer improvement was caused by the deposited layer on the inner surface of the evaporator. The layer affects not only the roughness but also the surface energy, wettability, and surface tension at the evaporator wall.

- Although there were almost no differences in transport heat capabilities for the high heat fluxes, the timedependent behaviour of tested fluids was substantially different. For water and graphene oxide nanofluid, the main boiling regime for high temperatures of the evaporator was geyser boiling. The phenomenon was inhibited by the SDS because the surfactant reduced surface tension. It prevented the formation of large bubbles expelling working fluid towards the condenser.

- The surface chemistry of GO nanoparticles played a key role in avoiding geyser boiling. Even though the graphene oxide nanofluid was stabilised with SDS, it did not prevent geyser boiling because most of the SDS was attached to the surface of the GO flakes. In result, there was not enough surfactant in the solution to suppress geyser formation.

- The amplitude and the frequency of geysers depended on temperatures in the evaporator and condenser sections. Increases in temperature difference between evaporator and condenser led to shorter and less intensive geysers.

- Geyser boiling did not affect overall thermal resistance of the device for high heat load region.

- Non-dimensional representation of the boiling curves which would be based on similarity numbers relevant for the effects observed in the thermosyphon does not exist. This is at least partly due to the fact that boiling regimes are changing when increasing the provided amount of heat at the evaporator.

Acknowledgements This work is a contribution to the Grant MF140079 and the NanoUptake COST Action (European Cooperation in Science and Technology) CA15119: Overcoming Barriers to Nanofluids Market Uptake. The authors wish to thank Mr Tietze and Mrs Martinez for their contributions to the preparation of the test rig and photographs presented herein.

Open Access This article is distributed under the terms of the Creative Commons Attribution 4.0 International License (http://creative commons.org/licenses/by/4.0/), which permits unrestricted use, distribution, and reproduction in any medium, provided you give appropriate credit to the original author(s) and the source, provide a link to the Creative Commons license, and indicate if changes were made.

\section{References}

1. Bianco V, Manca O, Nardini S, Vafai K. Heat Transfer Enhancement with nanofluids. Boca Raton: CRC Press; 2015.

2. Buschmann MH. Nanofluids in thermosyphons and heat pipes: overview of recent experiments and modelling approaches. Int $\mathrm{J}$ Therm Sci. 2014;72:1-17. 
3. Das SK. Nanofluids-the cooling medium of the future. Heat Transf Eng. 2006;27(10):1-2.

4. Choi S, Eastman JA. Enhancing thermal conductivity of fluids with nanoparticles. In: ASME international mechanical engineering congress, San Francisco, 1995

5. Grab T, Gross U, Franzke U, Buschmann MH. Operation performance of thermosyphons employing titania and gold nanofluids Int. J Therm Sci. 2014;86:352-64.

6. Kim KM, Bang IC. Effects of graphene oxide nanofluids on heat pipe performance and capillary limits. Int $\mathrm{J}$ Therm Sci. 2016;100:346-56.

7. Walunj AA, Pathan FZ, Shaikh AA, Hussein AK. Heat transfer enhancement in heat pipe using nanofluid-a review. Int $\mathrm{J}$ Theor Appl Res Mech Eng. 2015,1:65-70.

8. Gupta NK, Tiwari AK, Ghosh SK. Heat transfer mechanisms in heat pipes using nanofluids-A review. Exp Therm Fluid Sci. 2018;90(6):84-100.

9. Buschmann MH, Azizian R, Kempe T, Juliá JE, Martínez-Cuenca R, Sundén B, Wu Z, Seppälä A, Ala-Nissila T. Correct interpretation of nanofluid convective heat transfer. Int $\mathrm{J}$ Therm Sci. 2018;129:504-31.

10. Buschmann MH, Huminic A, Mancin S, Riehl R, Huminic G. State of the art of heat transfer of heat pipes and thermosyphons employing nanofluids as working fluid. J Nanofluids, 2018 (accepted).

11. Ambreen T, Kim MH. Heat transfer and pressure drop correlations of nanofluids: a state of art review. Renew Sustain Energy Rev. 2018;91:564-83.

12. Kakaç S, Pramuanjaroenkij A. Review of convective heat transfer enhancement with nanofluids. Int $\mathrm{J}$ Heat Mass Transf. 2009;52(13-14):3187-96.

13. Tetreault-Friend M, Azizian R, Bucci M, McKrell T, Buongiorno J, Rubner M, Cohen R. Critical heat flux maxima resulting from the controlled morphology of nanoporous hydrophilic surface layers. Appl Phys Lett. 2016;108:243102.

14. Wang Z, Wu Z, Han F, Wadsö L, Sundén B. Experimental comparative evaluation of a graphene nanofluid coolant in miniature plate heat exchanger. Int $\mathbf{J}$ Therm Sci. 2018;130:148-56.

15. Rashidi S, Eskandarian M, Mahian O, Poncet S. Combination of nanofluid and inserts for heat transfer enhancement. J Therm Anal Calorim. 2018;9:1-24.

16. Quan X, Wang D, Cheng P. An experimental investigation on wettability effects of nanoparticles in pool boiling of a nanofluid. Int J Heat Mass Transf. 2017;108:32-40.

17. Kamatchi R, Venkatachalapathy S, Abhinaya Srinivas B. Synthesis, stability, transport properties, and surface wettability of reduced graphene oxide/water nanofluids. Int $\mathbf{J}$ Therm Sci. 2015;97:17-25.

18. Murshed SMS, Estellé P. A state of the art review on viscosity of nanofluids Renew. Sustain Energy Rev. 2017;76:1134-52.

19. Huminic A, Huminic G, Fleaca C, Dumitrache F, Morjan I. Thermal conductivity, viscosity and surface tension of nanofluids based on FeC nanoparticles. Powder Technol. 2015;284:78-84.

20. Żyła G. Viscosity and thermal conductivity of MgO-EG nanofluids: experimental results and theoretical models predictions. J Therm Anal Calorim. 2017;129:171-80.

21. Cabaleiro D, Navas H, Desforges A. Dynamic viscosity and surface tension of stable graphene oxide and reduced graphene oxide aqueous nanofluid. J Nanofluids. 2018;7:1-8.

22. Ferrer G, Barreneche C, Solé A, Martorell I, Cabeza LF. New proposed methodology for specific heat capacity determination of materials for thermal energy storage (TES) by DSC. J Energy Storage. 2017;11:1-6.

23. Izadkhah MS, Erfan-Niya H, Heris SZ. Influence of graphene oxide nanosheets on the stability and thermal conductivity of nanofluids. J Therm Anal Calorim. 2018. https://doi.org/10.1007/ s10973-018-7100-7.

24. Estellé P, Cabaleiro D, Żyła G, Lugo L, Murshed SMS. Current trends in surface tension and wetting behavior of nanofluids. Renew Sustain Energy Rev. 2018;94:931-44.

25. Vasiliev LL, Grakovich LP, Rabetskii MI, Vasiliev LL Jr. Heat transfer enhancement in heat pipes and thermosyphons using nanotechnologies (nanofluids, nanocoatings, and nanocomposites) as an hp envelope. Heat Pipe Sci Technol Int J. 2013;4:251-75.

26. Poplaski LM, Benn SP, Faghri A. Thermal performance of heat pipes using nanofluids. Int J Heat Mass Transf. 2017;107:358-71.

27. Azizi M, Hosseini M, Zafarnak S, Shanbedi M, Amiri A. Experimental analysis of thermal performance in a two-phase closed thermosiphon using graphene/water nanofluid. Ind Eng Chem Res. 2013;52(29):10015-21.

28. Amiri A, Sadri R, Shanbedi M, Ahmadi G, Chew BT, Kazi SN, Dahari M. Performance dependence of thermosyphon on the functionalization approaches: an experimental study on thermophysical properties of graphene nanoplatelet-based water nanofluids. Energy Convers Manag. 2015;92:322-39.

29. Nazari MA, Ghasempour R, Ahmadi MH, Heydarian G, Shafii MB. Experimental investigation of graphene oxide nanofluid on heat transfer enhancement of pulsating heat pipe. Int Commun Heat Mass Transf. 2018;91:90-4.

30. Afzal A, Nawfal I, Mahbubul IM, Kumbar SS. An overview on the effect of ultrasonication duration on different properties of nanofluids. J Therm Anal Calorim. 2018. https://doi.org/10.1007/ s10973-018-7144-8.

31. Vafaei S, Borca-Tasciuc T. Role of nanoparticles on nanofluid boiling phenomenon: nanoparticle deposition. Chem Eng Res Des. 2014;92(5):842-56.

32. Kim SJ, Bang IC, Buongiorno J, Hu LW. Study of pool boiling and critical heat flux enhancement in nanofluids. Bull Pol Acad Sci. 2007;55(2):211-6.

33. Kwark SM, Kumar R, Moreno G, Yoo J, You SM. Pool boiling characteristics of low concentration nanofluids. Int J Heat Mass Transf. 2010;53(5-6):972-81.

34. Seo C, Jang D, Chae J, Shin S. Altering the coffee-ring effect by adding a surfactant-like viscous polymer solution. Sci Rep Nat. 2017;7:500.

35. Smith K, Robinson AJ, Kempers R. Confinement and vapour production rate influences in closed two-phase reflux thermosyphons Part A: flow regimes. Int $\mathrm{J}$ Heat Mass Transf. 2019;119:907-21.

36. Smith K, Robinson AJ, Kempers R. Confinement and vapour production rate influences in closed two-phase reflux thermosyphons Part B: heat transfer. Int J Heat Mass Transf. 2019;120:1241-54.

37. Casarosa C, Latrofa E, Shelginski A. The geyser effect in a twophase thermosyphon. Int J Heat Fluid Flow. 1982;26:933-41.

38. Lin TF, Lin WT, Tsay YL, Wu JC, Shyu RJ. Experimental investigation of geyser boiling in an annular two-phase closed thermosyphon. Int J Heat Mass Transf. 1995;38(2):295-307.

39. Khazaee I, Hosseini R, Noie SH. Experimental investigation of effective parameters and correlation of geyser boiling in a twophase closed thermosyphon. Appl Therm Eng. 2010;30(5):406-12.

40. Tong LL, Shao G, Yuan K, Cao XW. An experimental study on geysering phenomena induced by buoyancy in a heating system. Ann Nucl Energy. 2014;63:129-37.

41. Franzke U, Buschmann MH. Gold nanofluid prevents geyser effect in thermosyphon. In: The 8th international symposium on turbulence, heat and mass transfer, Sarajevo, Bosnia and Herzegovina; 2015, 15-18 September 2015. http://www.thmt-15.org. 
42. Wlazlak A, Zajaczkowski B, Barison S, Agresti F, Wilde LM, Buschmann MH. Nanofluids as working fluid in thermosyphon. In: 1st European Symposium Nanofluids, Abstract Coll., 2017:172-177.

43. Shanbedi M, Zeinali Heris S, Maskooki A. Experimental investigation of stability and thermophysical properties of carbon nanotubes suspension in the presence of different surfactants. J Therm Anal Calorim. 2015;120:1193-201.

44. Sadeghinezhad E, Mehrali M, Saidur R, Mehrali M, Tahan Latibari S, Akhiani AR, Metselaar HSC. Experimental investigation of stability and thermophysical properties of carbon nanotubes suspension in the presence of different surfactants. J Therm Anal Calorim. 2015;120:1193-201.

45. Kang JH, Kim T, Choi J, Park J, Kim YS, Chang MS, Jung H, Park KT, Yang SJ, Park CR. Hidden second oxidation step of hummers method. Chem Mater. 2016;28(3):756-64.

46. Buschmann $\mathrm{MH}$, Franzke U. Improvement of thermosyphon performance by employing nanofluid. Int $\mathrm{J}$ Refrig. 2014;40:416-28.

47. Forrest E, Williamson E, Buongiorno J, Hu LW, Rubner M, Cohen R. Augmentation of nucleate boiling heat transfer and critical heat flux using nanoparticle thin-film coatings. Int $\mathrm{J}$ Heat Mass Transf. 2010;53:58-67.

48. Li X, Cheung SCP, Tu J. Nucleate boiling of dilute nanofluidsmechanism exploring and modelling. Int $J$ Therm Sci. 2014;84:323-34.

49. Moreno G, Jeffers JR, Narumanchi S. Effects of pressure and a microporous coating on HFC-245fa pool boiling heat transfer. J Heat Transf. 2014;136(10):101502.
50. Ahn HS, Kim JM, Kim MH. Experimental study of the effect of a reduced graphene oxide coating on critical heat flux enhancement. Int J Heat Mass Transf. 2013;60:763-71.

51. Ahn HS, Kim JM, Kaviany M, Kim MH. Pool boiling experiments in reduced graphene oxide colloids. Part I-boiling characteristics. Int J Heat Mass Transf. 2014;74:501-12.

52. Park SD, Lee SW, Kang S, Bang IC, Kim IH, Shin HS, Lee DW, Lee DW. Effects of nanofluids containing graphene/grapheneoxide nanosheets on critical heat flux. Appl Phys Lett. 2010;97:023103.

53. Zhu Y, Murali S, Cai W, Li X, Suk JW, Potts JR, Ruoff RS. Graphene and graphene oxide: synthesis, properties, and applications. Adv Mater. 2010;22(35):3906-24.

54. Montes-Navajas P, Asenjo NG, Santamaría R, Menéndez R, Corma A, García H. Surface area measurement of graphene oxide in aqueous solutions. Langmuir. 2013;29(44):13443-8.

55. Wang J, Li FC, Li XB. Bubble explosion in pool boiling around a heated wire in surfactant solution. Int $\mathrm{J}$ Heat Mass Transf. 2016;99:569-75.

56. Wang J, Li FC, Li XB. Bubble explosion in pool boiling around a heated wire in surfactant solution. Int $\mathrm{J}$ Heat Mass Transf. 2016;99:569-75.

57. Acharya A, Pise A. A review on augmentation of heat transfer in boiling using surfactants/additives. Heat Mass Transf. 2016;53(4):1-21. 